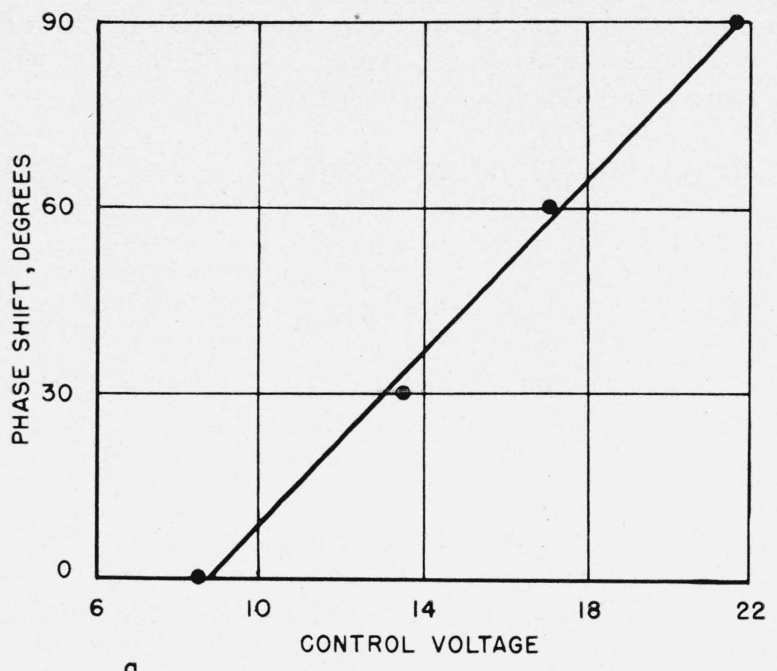

a

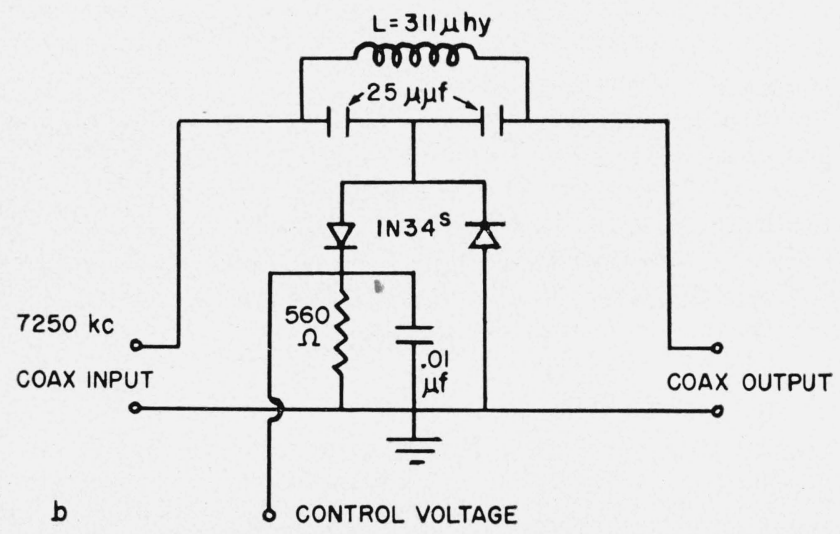

Figure 11. Phase shift versus control voltage for bridged-tee phase modulator $(f=7,250 \mathrm{kc})$. work during modulation is not generally serious, since the input reactance of the network decreases to only $-j 4 X_{C} / 3$ ohms when $R_{2}$ becomes zero.

Another application of the bridged-tee of figure 3 is suggested by the previously mentioned property of this network of giving constant attenuation with variation in frequency as shown in figure $4, \mathrm{~b}$. Two bridged-tee networks in tandem, properly adjusted, result in a constant phase shift independent of frequency over a wide range. This combination of bridged-tee networks may have advantages over lattice networks that have been described recently $[5,6]$ for this purpose, particularly since the bridged-tee is single-ended and functions when loaded. Hence, no phase-inverting and isolating vacuum tube amplifiers should be required with this bridged-tee arrangement, although the attenuation through the two bridged-tee networks may be a disadvantage in some applications.

\section{References}

[1] F. E. Terman, Radio engineers' handbook, p. 918 (McGraw-Hill Book Co., New York, N. Y., 1943).

[2] I. A. Greenwood, Jr., J. V. Holdam, Jr., and D. MacRae, Jr., Electronic instruments, Radiation Laboratory Series 21, 230 (McGraw-Hill Book Co., Inc., New York, N. Y., 1948).

[3] E. A. Guillemin, A method of representing the insertion loss and angle of symmetrical networks (manuscript circulated to staff members of Radiation Laboratory during World War II).

[4] H. Lauer, R. Lesnick, and L. Matson, Servomechanism fundamentals, 1st ed., p. 158 (McGraw-Hill Book Co., Inc., New York, N. Y., 1947).

[5] R. B. Dome, Wide-band phase shift networks, Electronics 19, 112 to 115 (Dec. 1946).

[6] David G. C. Luck, Properties of some wide-band phaselifting networks, Proc. IRE 37, 147 to 151 (Feb. 1949).

Washington, March 28, 1950.

\title{
Stability of Dextrose Solutions of Varying $\mathrm{pH}$
}

\section{By Emma J. McDonald}

\begin{abstract}
A study has been made of the rate of the initial decomposition reaction taking place in dextrose solutions of varying $\mathrm{pH}$. From the change in direct optical rotation over a period of time velocity constants have been calculated for eight values of $\mathrm{pH}$. The results indicate that dextrose solutions are most stable at about $\mathrm{pH} 4$.
\end{abstract}

\section{Introduction}

A great deal of work has been reported in the literature concerning the decomposition of reducing sugars in acid and in alkaline solutions. However, there is little to be found that gives an explanation or measure of the relation that exists between the $\mathrm{pH}$ and the stability of aqueous dextrose solutions. The wide use of dextrose solutions as standards in methods of sugar analysis has led to this investigation. In addition, aqueous solutions of dextrose find application in the practice of medicine where the solutions are stored in a sterile condition in ampoules or in bottles. A great variety of food products, both naturally occurring and manufactured, contain dextrose, often as one of the main constituents. Fruit juices, honey, table sirups, and molasses are examples of this group.

In the presence of aqueous acids, dextrose undergoes condensation reactions, forming disaccharides and possibly higher oligosaccharides. The products of this primary reaction, as is to be expected, are of great variety as the mode of attachment of two dextrose molecules is unselective and depends upon the 
párticular hydrogen and hydroxyl removed during the condensation. Some authors have grouped the products together under the name isomaltose. ${ }^{1}$

From this mixture, as well as from "hydrol," the molasses of the dextrose industry, the disaccharide gentiobiose [1], ${ }^{2}$ has been isolated.

By evaporating a 10-percent solution of dextrose in 1 percent of hydrochloric acid, Levene and Ulpts [2] obtained a disaccharide not further identified but having a specific rotation of $95^{\circ}$ and only 12 percent of the reducing power of dextrose. More drastic action of acids on dextrose causes further dehydration. In general, hydroxymethylfurfural is formed by the removal of three molecules of water, and further loss of water results in the formation of formic acid and levulinic acid.

In alkaline solution, the familiar Lobry de BruynVan Ekenstein transformation [3] occurs leading to an equilibrium between dextrose, levulose, and mannose, established by rearrangement of the common enediol. Kusin [4] reports that after 24 hours a glucose solution made alkaline with sodium hydroxide contained fructose and very little mannose. He found that the equilibrium composition is dependent upon the alkaline reagent used. Nef [5] has shown that the prolonged action of relatively strong alkali leads to a complete disintegration of the dextrose molecule with the possible formation of about 116 products. The discoloration of dextrose solutions and particularly that related to the initial decomposition is of interest to the canning industry. Therefore studies have been made concerning the color produced when dextrose solutions are heated under conditions used in preserving fruits and vegetables. Kroner and Kathe [6] have related the intensity of discoloration of 40-percent-dextrose solutions to $\mathrm{pH}$. The values of the extinction coefficient (as measured with a Zeiss Pulfrich photometer) rapidly decreases from $\mathrm{pH} 1$ to $\mathrm{pH} 2$ and passes thru a minimum at approximately $\mathrm{pH} 2.5$. After this point the color increases with $\mathrm{pH}$. The minimum of discoloration therefore takes place between $\mathrm{pH} 2$ and $\mathrm{pH} 3$.

The present investigation is to be interpreted as qualitative in its findings; however, it does denote the relative stability of dextrose solutions where the rate of reaction can be followed. As to that range between $\mathrm{pH} 1$ and $\mathrm{pH} 7$ where decomposition takes place very slowly at $30^{\circ} \mathrm{C}$, it is to be expected that the rate of decomposition continues in the trend indicated by the measured values. Experiments run at $100^{\circ}$ and $70^{\circ} \mathrm{C}$ show this to be the case at these temperatures.

\section{Method}

In this work measurements have been made of the initial rate of decomposition of dextrose solutions of varying $\mathrm{pH}$. This requires the determination of

\footnotetext{
1 The term isomaltose has also been provisionally used to designate $6-\alpha$-D-
glucopyranosyl- $\beta$-D-glucopyranose. Although this sugar has not been obtained in crystalline form it has been identified by means of its crystalline octaacetate. (M. L. Wolfrom, L. W. Georges and I. L. Miller, J. Am. Chem. Soc. 71, 125 (1949).

${ }_{2}$ Figures in brackets indicate the literature references at the end of this paper.
}

small changes in dextrose content. Except in the range of high acidity or alkalinity, these changes take place over a considerable period of time. The calculations involved in this study are based upon the change in optical rotation of a solution rather than on the determination of accurate specific rotations. Polariscopic measurements have the advantage of being a direct measurement of the change taking place with less error in reproducibility than one obtains with chemical methods. In some instances the products of decomposition alter the $\mathrm{pH}$ of the solution during the time of study. The $\mathrm{pH}$ of each solution was tested at various intervals and the adjustments required to obtain approximate constancy made. As it is impractical to follow the reaction until equilibrium is established, the procedure described by Jackson and Matthews ${ }^{3}$ [7] in their study of the stability of levulose has been used in determining the equilibrium toward which this initial reaction is progressing. It is assumed that the decomposition reaction under consideration is unimolecular. The fact that essentially the same velocity constant is obtained for two solutions of different concentrations at a given $\mathrm{pH}$ substantiates this assumption. Uncertainties introduced by the complex nature of the reactions and the method of analysis limit the accuracy of the determination of velocity constants to \pm 50 percent.

In alkaline solution the period of time during which the reaction can be followed polariscopically is limited by discoloration. In acid solution there is no limit, but the time required to reach equilibrium is prohibitive. The results are therefore applicable only for comparing the stability of dextrose solutions during the initial decomposition period. In considering the keeping qualities of a dextrose solution, whether for use as a standard solution or for other purposes as discussed above, the chemist is concerned with the initial changes and hence with the decomposition reaction before the side reactions begin.

Pure dextrose hydrate was dissolved in buffer solutions of systematically varying $\mathrm{pH}$ to form solutions of about 10 percent with respect to anhydrous sugar. ${ }^{4}$ For studying the more rapid reactions, a 50 -percent solution of sugar was prepared that permitted rapid mixing after both the buffer and sirup solutions has acquired the temperature of the bath. The buffer solutions were prepared according to Clark and Sørensen [8]. When it was practical,

\footnotetext{
3 "The following details for calculating the equilibrium are quoted from [7]. "Polarizations are observed or read from a curve at exactly equal intervals of time. If $a, b, c, d$, etc. are the polarizations at the times, $t_{1}, t_{2}, t_{3}, t_{4}$, etc., the time of the form.

$$
k=\frac{1}{t_{2}-t_{1}} \log \frac{a-x}{b-x}
$$

in which $k$ is the unknown velocity constant and $x$ the polarization at equilibrium. Elimination of $k$ between two of these equations gives

But as $t_{2}-t_{1}=t_{4}-t_{3}$

$$
\frac{1}{t_{2}-t_{1}} \log \frac{a-x}{b-x}=\frac{1}{t_{4}-t_{3}} \log \frac{c-x}{d-x}
$$

Solving for $x$,

$$
\frac{a-x}{b-x}=\frac{c-x}{d-x}
$$

$$
x=\frac{a d-b c}{a+d-b-c} .
$$

${ }^{4}$ When necessary mercuric iodide was used to prevent the growth of mold.
} 
TABLE 1. Hydrochloric acid and buffer solutions

\begin{tabular}{|c|c|c|c|c|c|}
\hline $\begin{array}{c}\text { Aver- } \\
\text { age } \\
\text { pH }\end{array}$ & $\begin{array}{c}\text { Range of } \\
\mathrm{pH}\end{array}$ & Buffer & $\begin{array}{l}\text { Aver- } \\
\text { age } \\
\text { pH }\end{array}$ & $\begin{array}{c}\text { Range of } \\
\mathrm{pH}\end{array}$ & Buffer \\
\hline $\begin{array}{l}-2.61 \\
-1.80 \\
-1.43 \\
+0.10\end{array}$ & $\begin{array}{l}\begin{array}{l}\text { Not meas- } \\
\text { ured. }\end{array} \\
\\
\end{array}$ & $\begin{array}{l}14.5 \mathrm{M} \mathrm{HCl} \text {. } \\
8.83 \mathrm{M} \mathrm{HCl} \text {. } \\
6.81 \mathrm{M} \mathrm{HCl} \text {. } \\
1 \mathrm{M} \mathrm{HCl} .\end{array}$ & $\begin{array}{r}8.0 \\
8.6 \\
9.6 \\
10.7 \\
12.1\end{array}$ & $\begin{array}{c}8.0 \\
9.1 \text { to } 8.1 \\
9.8 \text { to } 9.4 \\
10.8 \text { to } 10.6 \\
12.2 \text { to } 12.0\end{array}$ & $\begin{array}{l}\mathrm{KH}_{2} \mathrm{PO}_{4}, \mathrm{NaOH} . \\
\text { glycine, } \mathrm{NaOH} . \\
\text { Do. } \\
\text { Do. } \\
\mathrm{Na}_{2} \mathrm{HPO}_{4}, \mathrm{NaOH} .\end{array}$ \\
\hline
\end{tabular}

the dry constituents were added to the sugar solution. The $\mathrm{pH}$ of the resulting solution was measured with a glass electrode, and the measured value was used in the tabulation. The buffers used in the individual experiments are given in table 1.

The $\mathrm{pH}$ of the hydrochloric acid solutions were calculated from the work of Harned and Ehlers [9] and of Akerlof and Teare [10]. If one assumes that the activity of the hydrogen ion is equal to that of the hydrochloric acid, the $\mathrm{pH}$ of the solution may be calculated by the following formula:

$$
\mathrm{pH}=-\log m_{H} \cdot \gamma_{H C l}=-\left(\log m_{H}+\log \gamma_{H C l}\right),
$$

where $m=$ molality, $\gamma=$ activity coefficient.

The reactions were followed by observing the change in optical rotation that took place over a period of time. These measurements were made with a Bates-type quartz wedge saccharimeter in a water jacketed polariscope tube. All polarizations at a given $\mathrm{pH}$ were measured under identical conditions in order to avoid errors that might enter if corrections had to be made for temperature and volume.

The decomposition of a dextrose solution at $70^{\circ} \mathrm{C}$, in 5 molal hydrochloric acid $(\mathrm{pH}-0.92)$ was followed by observing polarization, by Munson and Walker's method [11] for reducing sugars, and by Somogyi's selective fermentation method in order to be assured that the value of $k$ was independent of the method used in following the reaction. Table 2 shows the results of this comparison. It was concluded that in the acid region change of polarization might be used as a criterior of the initial rate of decomposition.

The details of the fermentation method are given since some modifications of the author's procedure were used. Somogyi [12] showed that in dextrose-

Table 2. Decomposition of dextrose at $70^{\circ} \mathrm{C}$ in $5 \mathrm{M} \mathrm{HCl}$ $p H-0.92$

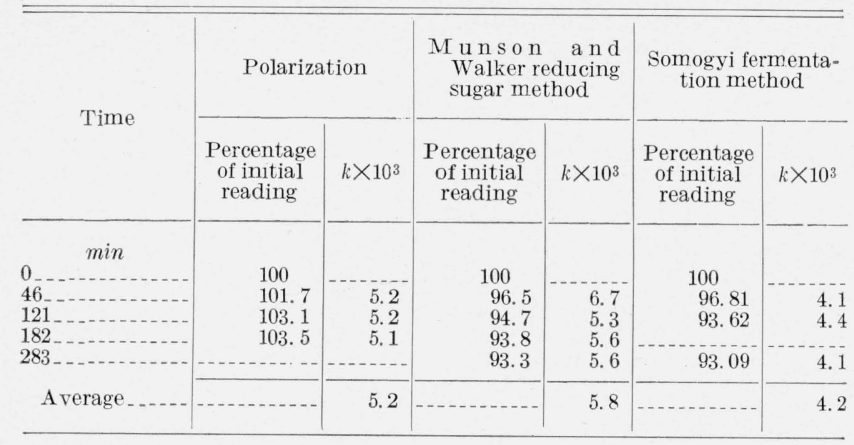

maltose mixtures the fermentation of maltose can be completely suppressed during a period of time sufficient for the complete fermentation of dextrose if the $\mathrm{pH}$ of the solution is held at 7.2 to 7.4 . The difference in reducing sugar before and after fermentation is then a measure of dextrose. In using the method, it was assumed that any other sugar likely to have been formed in the mixture was at least as resistant to fermentation as maltose.

It was found convenient to use ordinary yeast cakes for the fermentation. These were washed by suspension in water and centrifugal sedimentation. In the sediment first obtained the starch settled out in a clearly visible layer at the bottom of the conical centrifuge tube. About two-thirds of the yeast, essentially free from starch, was scraped off and washed in the same manner three times more. From each yeast cake (13 grams) about 9 grams of moist sedimented yeast was obtained. To this was added an equal weight of water, which yielded a suspension thin enough to be drawn into a pipette and roughly measured. Four milliliters corresponding to 2 grams of moist yeast was used for an analysis.

Test tubes $(17 \times 150 \mathrm{~mm})$ were graduated with indelible ink at the $25-\mathrm{ml}$ volume point. Two identical samples of the sugar solution were taken, each containing about $7 \mathrm{mg}$ of sugar. One sample was transferred to a calibrated test-tube, the other to a $25-\mathrm{ml}$ volumetric flask. The sample in the testtube was diluted to about $15 \mathrm{ml}$, and $4 \mathrm{ml}$ of the yeast suspension was added. One drop of phenol red was added and the solution was kept perceptibly pink by dropwise addition of $0.2 \mathrm{~N}$ sodium hydroxide. A rubber stopper was inserted and the test-tube was inverted after each addition to insure thorough mixing. The fermentation proceeded rapidly and was usually practically complete in 6 to 7 minutes. It was allowed, however, to continue for 25 minutes. The tube was then filled to the 25-ml mark, mixed, and sedimented. A 5-ml aliquot was taken for analysis.

Reducing sugar was determined in the samples by Somogyi's modification of Shaffer and Hartmann's micro method [11].

In the alkaline region, a 12.5-molal sodium hydroxide solution of $\mathrm{pH} 12.1$ containing dextrose was kept at $5^{\circ} \mathrm{C}$, and the change followed by direct polarization measurements and by Munson and Walker's method for reducing sugar. Although the latter method is not selective for dextrose in the presence of levulose and mannose, the difference in the reducing effect of these sugars on the reagent was sufficient that it could be used as a measure of the change that was taking place. At this temperature the change was slow, making a considerable number of observations possible. The agreement in the values for $k$ arrived at by the two methods is well within the experimental error as shown in table 3 .

\section{Experimental Data and Conclusions}

Thirty degrees centigrade was selected as the most suitable temperature at which to carry on the series of reactions. The solutions were prepared as 
described previously, and the polarization observations were made at time intervals depending upon the rate of the reaction in question. Table 4 gives the

TABle 3. Decomposition of dextrose at $5^{\circ} \mathrm{C}$ in $12.5 \mathrm{M} \mathrm{NaOH}$ $(p H-12.1)$

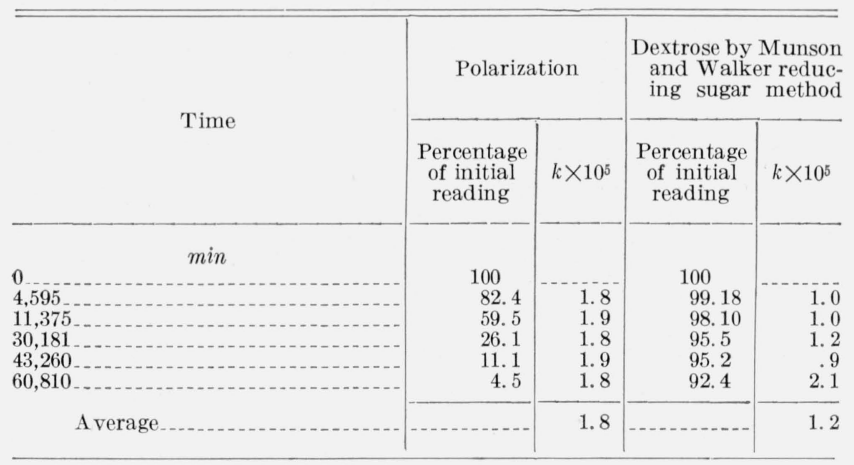

TABLE 4. Experimental data at $30^{\circ} \mathrm{C}$

\begin{tabular}{|c|c|c|c|}
\hline Time & Rotation ${ }^{\circ} \mathrm{S}$ & Time & Rotation ${ }^{\circ} S$ \\
\hline \multicolumn{2}{|c|}{$\mathrm{pH}-2.6$} & \multicolumn{2}{|c|}{$\mathrm{pH} 8$} \\
\hline \multirow{2}{*}{$\begin{array}{r}\min \\
0 \\
3 \\
72 \\
150 \\
225 \\
310 \\
439\end{array}$} & \multirow{2}{*}{$\begin{array}{l}\text { 30. } 53 \\
\text { 30. } 59 \\
31.34 \\
\text { 31. } 96 \\
32.33 \\
32.80 \\
33.31\end{array}$} & $\begin{array}{c}\min \\
50,0 \\
54,900 \\
94,985\end{array}$ & $\begin{array}{l}26.81 \\
26.39 \\
26.33\end{array}$ \\
\hline & & lo & $1^{7 \times 10^{-7}}$ \\
\hline \multicolumn{2}{|c|}{$\begin{aligned} k & =2.2 \times 10^{-2} \\
\log 1 / k & =1.6\end{aligned}$} & \multicolumn{2}{|c|}{$\mathrm{pH} 8.6$} \\
\hline \multicolumn{2}{|c|}{$\mathrm{pH}-1.78$} & $\min _{0}$ & \\
\hline \multirow{2}{*}{$\begin{array}{l}\min _{0} \\
1,364 \\
3,015 \\
4,345 \\
8,940\end{array}$} & \multirow{2}{*}{$\begin{array}{l}31.74 \\
33.23 \\
33.89 \\
34.50 \\
35.05\end{array}$} & $\begin{array}{r}1,463 \\
11,360 \\
71,760 \\
215,926\end{array}$ & $\begin{array}{l}27.56 \\
27.04 \\
25.08 \\
25.10\end{array}$ \\
\hline & & lo & $4 \times 10^{-6}$ \\
\hline \multicolumn{2}{|c|}{$\begin{aligned} k & =1.6 \times 10^{-4} \\
\log 1 / k & =3.8\end{aligned}$} & \multicolumn{2}{|c|}{$\mathrm{pH} 9.6$} \\
\hline \multicolumn{2}{|c|}{$\mathrm{pH}-1.44$} & $\begin{array}{r}\min 0 \\
0 \\
710\end{array}$ & $\begin{array}{l}30.07 \\
28.65\end{array}$ \\
\hline \multirow{2}{*}{$\begin{array}{r}\min \\
0 \\
1,360 \\
4,506 \\
7,236\end{array}$} & \multirow{2}{*}{$\begin{array}{l}31.02 \\
32.10 \\
32.85 \\
33.03\end{array}$} & $\begin{array}{r}1,361 \\
6,044 \\
15,840\end{array}$ & $\begin{array}{l}28.33 \\
26.68 \\
22.76\end{array}$ \\
\hline & & lo & $2 \times 10^{-5}$ \\
\hline \multicolumn{2}{|c|}{$\begin{aligned} k & =2.2 \times 10^{-4} \\
\log 1 / k & =3.6\end{aligned}$} & \multicolumn{2}{|c|}{$\mathrm{pH} 10.7$} \\
\hline \multicolumn{2}{|c|}{$\mathrm{pH} 0$} & $\begin{array}{l}\min \\
1.50\end{array}$ & $\begin{array}{l}29.78 \\
22.06\end{array}$ \\
\hline $\begin{array}{r}\text { min } \\
0 \\
191,660 \\
289,550 \\
423,530\end{array}$ & $\begin{array}{l}29.05 \\
30.10 \\
30.29 \\
30.38\end{array}$ & $\begin{array}{r}2,873 \\
4,636 \\
5,993 \\
9,960 \\
12,812 \\
20,460\end{array}$ & $\begin{array}{r}17.05 \\
12.82 \\
10.62 \\
7.48 \\
6.50 \\
6.05\end{array}$ \\
\hline \multicolumn{2}{|c|}{$\begin{aligned} k & =3.9 \times 10^{-6} \\
\log 1 k & =5.4\end{aligned}$} & \multicolumn{2}{|c|}{$\begin{aligned} k & =1.3 \times 10^{-4} \\
\log 1 / k & =3.9\end{aligned}$} \\
\hline
\end{tabular}

TABLE 5. Calculated equilibrium rotations expressed as percent of initial rotation

\begin{tabular}{|c|c||c|c|}
\hline $\mathrm{pH}$ & $\begin{array}{c}\text { Equilibrium } \\
\text { rotation }\end{array}$ & $\mathrm{pH}$ & $\begin{array}{c}\text { Equilibrium } \\
\text { rotation }\end{array}$ \\
\cline { 1 - 2 } & -108.5 & 8 & 76.6 \\
-2.6 & 107.0 & 8.6 & 70.0 \\
-1.78 & 106.6 & 9.6 & 65.0 \\
-1.44 & 104.6 & 10.7 & 25.0 \\
\hline 0 & & & \\
\hline
\end{tabular}

experimental data. The calculated equilibrium rotations are given in table 5 .

At each $\mathrm{pH}$ a different reaction or series of reactions is being considered. However, as the equilibrium rotation (table 5) toward which the individual reactions are proceeding has been calculated, the values of $k^{5}$ are independent of the reaction taking place. The values of $\log 1 / k$ have been plotted against $\mathrm{pH}$ and a curve of the form indicated by measurements at higher temperatures drawn through the points. This curve (fig. 1) indicates that dextrose solutions are most stable at some point between $\mathrm{pH} 3$ and $\mathrm{pH} 5$.

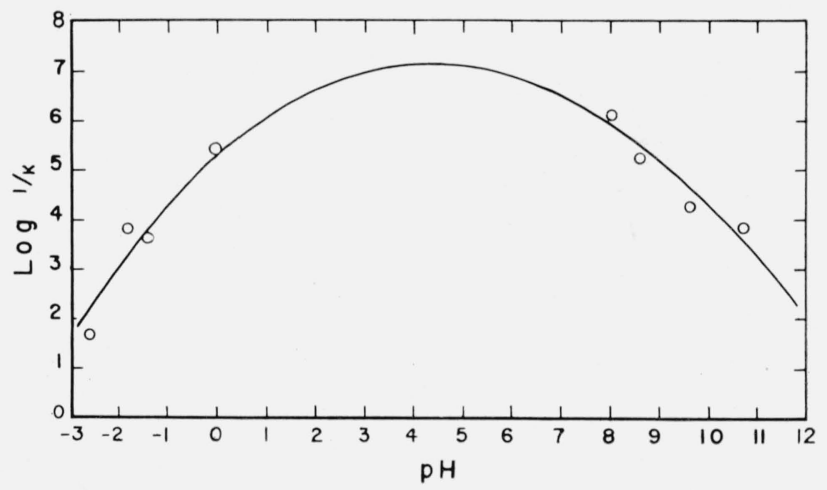

Figure 1. Relation between the initial rate of decomposition of aqueous dextrose solutions and their $p H$.

[1] H. Berlin, J. Am. Chem. Soc. 48, 2627 (1926).

[2] P. A. Levene and R. Ulpts, J. Biol. Chem. 64, 475 (1925).

[3] C. A. Lobry de Bruyn and W. A. Van Ekenstein, Rec. trav. chim. 14, 156, $203(1895) ; \mathbf{1 6}, 256$ (1897).

[4] A. Kusin, Ber. 69, 1041 (1936).

[5] J. U. Nef, Liebigs Ann. Chem. 335, 191 (1904); 35\%, 214 (1907); 376, 1 (1910); 403, 204 (1914).

[6] W. Kroner and H. Kathe, Ind. Eng. Chem. 31, 248 (1939).

[7] R. F. Jackson and J. A. Matthews, J. Research NBS 11, 619 (1933) RP611.

[8] W. M. Clark, The determination of hydrogen ions (The Williams and Wilkins Co., Baltimore, Md., 1928).

[9] H. S. Harned and R. W. Ehlers, J. Am. Chem. Soc. 54, $1350(1932) ; \mathbf{5 5}, 652,2179(1933)$.

[10] G. Akerlof and J. W. Teare, J. Am. Chem. Soc. 59, 1855 (1937).

[11] Official and Tentative Methods of the Association of Official Agricultural Chemists. 6th ed. (1945).

[12] M. Somogyi, J. Biol. Chem. 119, 741 (1937).

Washington, April 18, 1950.

\footnotetext{
${ }^{5}$ All values of $k$ are expressed in units of min- $^{-}$
} 